\title{
Osteonecrosis in SLE
}

\author{
M. Abeles $\cdot$ A. M. Abeles $\cdot$ J. Urman $\cdot$ N. Rothfield
}

Received: 20 September 2010 / Accepted: 30 December 2010 / Published online: 22 February 2011

(C) Springer-Verlag 2011

To the Editor,

Sayarlioglu et al. note that osteonecrosis $(\mathrm{ON})$ in patients with SLE is associated with higher doses of corticosteroids (CS) administered within 4 months as well as with total cumulative dose [1]. The records of 868 patients with SLE from four centers were reviewed. A total of 49 patients were identified as having ON, and 154 SLE patients were used as comparators. The data presented agree to some extent with previous data $[2,3]$. However, limitations of the study are such that it is difficult to lend any credence to the results. The obvious question that needs to be answered is whether ON patients were more ill and therefore treated more aggressively. The authors used no criteria to define the severity of disease in their patients. They do note that the ON patients had significantly more systems affected and that cytotoxic agents were used in a significantly higher proportion of patients with ON. This strongly suggests that the ON patients were sicker in which case no inference regarding the role of CS can be made. The patients are drawn from four centers with multiple physicians providing care. It is unlikely that the approach to care is similar and therefore there is an inherent bias to the data that the authors do not address nor appear to overcome. It is also not clear how the authors account for the total steroid doses given to each patient which reduces the certainty of their conclusion.

\section{References}

1. Sayarlioglu M, Yuzbasioglu N, Inanc M, Kamali S, Cefle A, Karaman O, Onat AM, Avan R, Cetin GY, Gul A, Ocal L, Aral O (2010) Risk factors for avascular bone necrosis in patients with systemic lupus erythematosus. Rheumatol Int. doi:10.1007/s00296010-1597-9

2. Abeles M, Urman JD, Rothfield NF (1978) Aseptic necrosis of bone in systemic lupus erythematosus. Relationship to corticosteroid therapy. Arch Intern Med 138(5):750-754

3. Weiner ES, Abeles M (1989) Aseptic necrosis and glucocorticosteroids in systemic lupus erythematosus: a reevaluation. J Rheumatol 16(5):604-608

M. Abeles $(\bowtie) \cdot$ A. M. Abeles $\cdot$ J. Urman $\cdot$ N. Rothfield

University of Connecticut Health Center,

Department of Medicine, Division of Rheumatology,

Farmington, CT, USA

e-mail: abeles@nso2.uchc.edu 